\title{
Risk factors affecting the difficulty of fiberoptic nasotracheal intubation
}

\author{
Seung-Hyun Rhee ${ }^{1 *}$, Hye Joo Yun ${ }^{2 *}$, Jieun Kim¹, Myong-Hwan Karm¹, Seung-Hwa Ryoo1, Hyun Jeong Kim', \\ Kwang-Suk $\mathrm{Se}^{1}$ \\ 'Department of Dental Anesthesiology, School of Dentistry, Seoul National University, Seoul, Korea \\ ${ }^{2}$ Department of Anesthesiology and Pain Medicine, Eunpyeong St. Mary's Hospital, College of Medicine, The Catholic University of \\ Korea, Seoul, Korea
}

\begin{abstract}
Background: The success rate of intubation under direct laryngoscopy is greatly influenced by laryngoscopic grade using the Cormack-Lehane classification. However, it is not known whether grade under direct laryngoscopy can also affects the success rate of nasotracheal intubation using a fiberoptic bronchoscpe, so this study investigated the same. In addition, we investigated other factors that influence the success rate of fiberoptic nasotracheal intubation (FNI).

Methods: FNI was performed by 18 anesthesiology residents under general anesthesia in patients over 15 years of age who underwent elective oral and maxillofacial operations. In all patients, the Mallampati grade was measured. Laryngeal view grade under direct laryngoscopy, and the degree of secretion and bleeding in the oral cavity was measured and divided into 3 grades. The time required for successful FNI was measured. If the intubation time was $>5$ minutes, it was evaluated as a failure and the airway was managed by another method. The failure rate was evaluated using appropriate statistical method. Receiver operating characteristic (ROC) curves and area under the curve (AUC) were also measured.

Results: A total of 650 patients were included in the study, and the failure rate of FNI was $4.5 \%$. The patient's sex, age, height, weight, Mallampati, and laryngoscopic view grade did not affect the success rate of FNI (P $>0.05)$. BMI, the number of FNI performed by residents $(\mathrm{P}=0.03)$, secretion $(\mathrm{P}<0.001)$, and bleeding $(\mathrm{P}<0.001)$ grades influenced the success rate. The AUCs of bleeding and secretion were 0.864 and 0.798 , respectively, but the AUC of BMI, the number of FNI performed by residents, Mallampati, and laryngoscopic view grade were $0.527,0.616,0.614$, and 0.544 , respectively.

Conclusion: Unlike in intubation under direct laryngoscopy, in the case of FNI, oral secretion and nasal bleeding had a significant effect on FNI difficulty than Mallampati grade or Laryngeal view grade.
\end{abstract}

Keywords: Difficult Intubation; Fiberoptic Nasotracheal Intubation; laryngeal View; Mallampati Grade; Risk Factors.

This is an Open Access article distributed under the terms of the Creative Commons Attribution Non-Commercial License (http://creativecommons.org/licenses/by-nc/4.0/) which permits unrestricted non-commercial use, distribution, and reproduction in any medium, provided the original work is properly cited.

\section{INTRODUCTION}

Nasotracheal intubation (NTI) offers the oral and maxillofacial surgeon wider scope of the surgical field in operations of the oral cavity, face, and neck [1]. Nasotracheal intubation involves inserting an endotracheal tube through the nasal cavity to the oropharynx, in which, under direct laryngoscopy, Magill forceps are used to advance the tube between the vocal cords and

Received: October 8, 2020 - Revised: October 16, 2020 - Accepted: October 23, 2020

${ }^{*}$ co-first: Two authors (Rhee and Yun) contributed equally to this study.

Corresponding Author: Kwang-Suk Seo, Department of Dental Anesthesiology, Seoul National University, School of Dentistry, 101 Daehak-ro, Jongno-gu, Seoul 03080, Korea

Tel: +82-2-2072-0622 Fax: +82-2-766-9427 E-mail: stone90@snu.ac.kr

Copyright(c) 2020 Journal of Dental Anesthesia and Pain Medicine 
into the trachea. If a difficult airway is anticipated, NTI may be performed using the videoscope [2]. When the oral anatomy is deviated from normal and mouth opening is limited, use of a flexible fiberoptic bronchoscpe for nasotracheal intubation is favorable [3].

If it is not in a cannot ventilate situation, fiberoptic nasotracheal intubation (FNI) can be carried out after induction of anesthesia or in certain cases awake FNI may be carried out. However in both cases, FNI may be unsuccessful [4]. To carry out FNI skillfully, adequate education is mandatory [5]. Even in case of a skillful anestheiologist, $4-5 \%$ of intubation failure occurs in FNI [6]. The main cause of failure is an anatomical anomaly in the oral or nasal cavity, but bleeding or secretion in the oral cavity may also be important factors [4].

There are many different methods for predicting the difficulty of intubation using direct laryngoscopy [7]. The modified Mallampati score is a relatively simple method and is most widely used for predicting airway management [8]. The Cormack and Lehane laryngoscopic grade system used to describe laryngeal inlet view is also widely accepted [9]. However, these methods predict the difficulty of intubation with a laryngoscope, and there have been few reports on the evaluation methods used to predict the difficulty of FNI.

In this study, we investigated whether the Mallampati score and Cormack and Lehane laryngoscopic grade can predict FNI difficulty. In addition, we also investigated whether bleeding or oral secretion may influence the difficulty of FNI. These results may be helpful in predicting the difficulty of NTI in clinical situations.

\section{METHODS}

This used the data from a prior study on FNI education of anesthesiology residents [5]. For this study, Institutional Review Board approval was obtained from Seoul National University Dental Hospital (SNUDH, No. L0605-12). The FNI was conducted by 18 second-year residents who had experienced five or more FNI.

\section{Patients}

From the 716 patients included in the previous study, apart from the excluded patients due to inability to check the Cormack and Lehane laryngoscopic grade due to awake FNI or loss of measured records, 650 patients were included. Moreover, Patients with American Society of Anesthesiologists physical class III or higher, and patients with lung or heart disease were excluded. Patients in whom a difficulty with nasotracheal intubation was anticipated due to nasal cavity obstruction, mass or deformity, and those undergoing emergency surgery were also excluded. If the use of mask ventilation was expected to be difficult, due to reasons such as severe maxillofacial deformities or mass in the oral cavity, or the visual field with laryngoscopy was not satisfactory due to trismus, patients were excluded.

\section{General anesthesia and Evaluation}

Standard preoperative evaluations such as medical history, vital signs, routine laboratory tests, electrocardiography (ECG), chest radiography, and interview were performed before surgery. Mallampati grade was evaluated before general anesthesia in all patients. Induction began after routine monitoring, such as pulse oximetry, ECG, non-invasive blood pressure, and sufficient pre-oxygenation was performed. Anesthesia was induced with $1 \%$ propofol $(1.5-2.5 \mathrm{mg} / \mathrm{kg})$ or thiopental $(4-5 \mathrm{mg} / \mathrm{kg})$ intravenously. After confirmation of loss of consciousness, $0.15 \mathrm{mg} / \mathrm{kg}$ vecuronium was injected for neuromuscular blockade. After the patient lost consciousness and the neuromuscular blocking agent was administered, the Cormack and Lehane laryngoscopic grade was recorded using a Macintosh direct laryngoscope. Then, FNI was performed by anesthesiology residents under supervision of the anesthesiologist. A flexible endoscope with a diameter of $4.2 \mathrm{~mm}$ (LF2, Olympus Co., Japan) was used. If the tube ID was $<5.5$ $\mathrm{mm}$, then a $2.8 \mathrm{~mm}$ tube (LF-DP, Olympus Co., Japan) was used. The nasal intubation tube was $6.5 \mathrm{~mm}$ (ID, internal diameter) PVC Rign-Adair-Elwyn (RAE) 
(A)

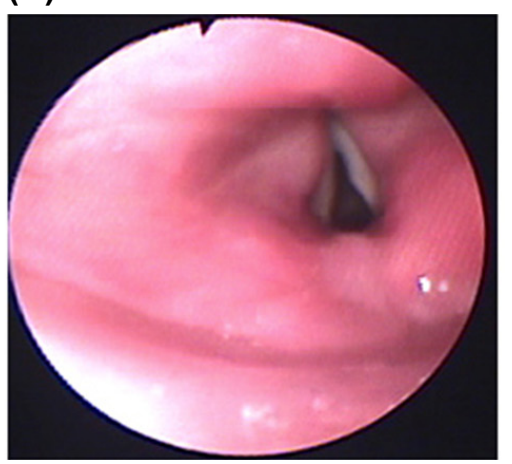

(B)

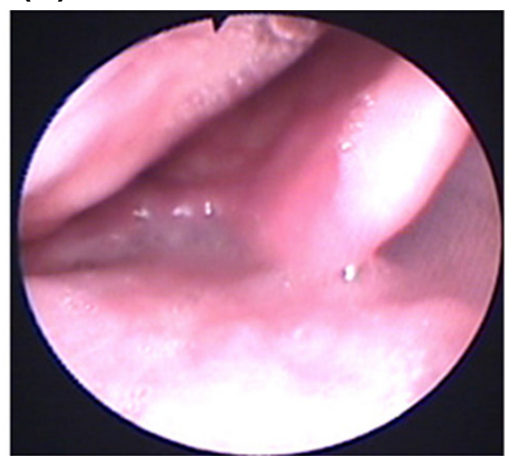

(C)

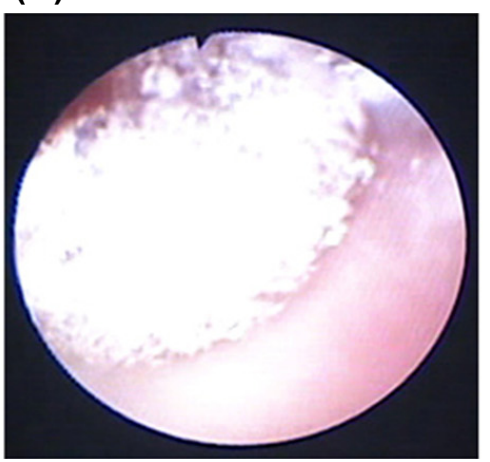

Fig. 1. Grade of intra-oral secretion. (A) No secretion (grade 1) (B) mild secretion; the degree of bleeding that does not influence fiberoptic nasal intubation (grade 2) (C) massive secretion; the degree of bleeding that influences fiberoptic nasal intubation (grade 3)

nasotracheal tube (cuffed) in female and $7.0 \mathrm{~mm}$ (ID) in male patients, and if the weight was less than $50 \mathrm{~kg}$, $5.5 \mathrm{~mm}$, or $6.0 \mathrm{~mm}$ (ID) was used. In order to reduce epistaxis, all RAE nasotracheal tubes were softened in hot water at $40^{\circ} \mathrm{C}$ and surgical jelly was applied. The RAE nasotracheal tube was inserted and placed in the nasopharynx. Fiberoptic bronchoscope was then inserted into the endotracheal tube, and was advanced to visualize the vocal cord. After fiberoptic bronchoscope passed through the vocal cord and carina was identified, the nasotracheal tube was placed in the trachea. At this time, the assistant performed jaw thrust to widen the oropharynx to ensure visibility.

After the procedure, each operator classified the fiberoptic view into three grades on the basis of nasal bleeding and intraoral secretion [5]. The degree of nasal bleeding and secretion was classified as grade 1 (no secretion, no interference with securing the visual field); grade 2 (mild secretion, the degree of secretion or bleeding that did not influence the visual field), and grade 3 (massive secretion, the degree that influenced the visual field) (Fig. 1). The success of FNI was assessed by the time and number of trials. After $2 \mathrm{~min}$ and $30 \mathrm{~s}$ on the first attempt, if unsuccessful, the patient was ventilated again with a bag mask. If the second attempt did not succeed even after $2 \mathrm{~min}$ and $30 \mathrm{~s}$, it was recorded as a failure. The time taken from the beginning to the end of intubation was recorded [6].

\section{Statistical Analysis}

The FNI was divided into two groups: success and failure. Continuous variables are presented as mean \pm standard deviation (SD). Categorical variables are presented as absolute numbers and percentages. Statistical methods included the Student $\mathrm{t}$ test, Chi square test, Fischer's exact test, and logistic regression analysis. Receiver operating characteristic (ROC) curves and area under the curve (AUC) were also used. Statistically significant differences were set at $\mathrm{P}<0.05$.

\section{RESULTS}

A total of 650 patients were included in the study. A total of $621(95.5 \%)$ patients underwent successful FNI and 29 (4.5\%) failed. The gender-specific demographic data of the patients included in the study and the distribution of factors measured during the intubation process are presented in Table 1 . The success rate of the procedure for 18 anesthesiology residents who performed FNI ranged from $92.9 \%$ to $100 \%$. As a result of the Fischer's exact test, there was no significant difference with a P-value of 0.952 . The most common reason for failure was secretion and bleeding in 25 patients (86.2\%). Next, two patients had difficulty in vocal cord exposure (6.9\%) and two had narrow nasal passages (6.9\%).

The factors for the FNI success group and the failure 
Table 1. Gender specific characteristics of patients and intubation state

\begin{tabular}{|c|c|c|c|c|}
\hline Gender & Male & Female & Total & $\begin{array}{c}\text { P-value } \\
\text { (Gender group) }\end{array}$ \\
\hline No. of Patients & $336(51.7 \%)$ & $314(48.3 \%)$ & 650 & \\
\hline Age (yr) & $34.7 \pm 16.0$ & $35.7 \pm 17.9$ & $35.1 \pm 16.9$ & 0.464 \\
\hline Height $(\mathrm{cm})$ & $171.8 \pm 7.2$ & $158.9 \pm 6.3$ & $165.6 \pm 9.3$ & $<0.001$ \\
\hline Weight $(\mathrm{kg})$ & $69.3 \pm 11.1$ & $56.0 \pm 9.2$ & $62.8 \pm 12.2$ & $<0.001$ \\
\hline BMl & $23.4 \pm 3.4$ & $22.2 \pm 3.5$ & $22.8 \pm 3.5$ & $<0.001$ \\
\hline ASA PS & & & & 0.062 \\
\hline 1 & 263 (78.3\%) & 246 (78.3\%) & 509 (78.3\%) & \\
\hline 2 & $71(21.1 \%)$ & $59(18.8 \%)$ & $130(20.0 \%)$ & \\
\hline 3 & $2(0.6 \%)$ & $9(2.9 \%)$ & $11(1.7 \%)$ & \\
\hline Tube size (mm) & & & & $<0.001$ \\
\hline 5.5 & $2(0.6 \%)$ & 0 & $2(0.3 \%)$ & \\
\hline 6.0 & 0 & $8(2.5 \%)$ & $8(1.2 \%)$ & \\
\hline 6.5 & $9(2.7 \%)$ & 301 (95.6\%) & $310(47.7 \%)$ & \\
\hline 7.0 & $325(96.7 \%)$ & $5(1.6 \%)$ & $330(50.8 \%)$ & \\
\hline Malampati grade & & & & 0.014 \\
\hline 1 & $194(58.6 \%)$ & 147 (46.8\%) & $344(52.9 \%)$ & \\
\hline 2 & $101(30.1 \%)$ & 122 (38.9\%) & $223(34.3 \%)$ & \\
\hline 3 & $29(8.6 \%)$ & $39(12.4 \%)$ & $68(10.5 \%)$ & \\
\hline 4 & $9(2.7 \%)$ & $6(1.9 \%)$ & $15(2.3 \%)$ & \\
\hline Laryngeal view grade & & & & 0.156 \\
\hline 1 & $232(69.0 \%)$ & 238 (75.8\%) & $470(72.3 \%)$ & \\
\hline 2 & 65 (19.3\%) & 45 (14.3\%) & $110(16.9 \%)$ & \\
\hline 3 & $33(9.8 \%)$ & $29(9.2 \%)$ & $62(9.5 \%)$ & \\
\hline 4 & $6(1.8 \%)$ & $2(0.6 \%)$ & $8(1.2 \%)$ & \\
\hline Nasal bleeding grade & & & & 0.526 \\
\hline 1 & 237 (70.5\%) & 211 (67.2\%) & 448 (68.9\%) & \\
\hline 2 & $56(16.7 \%)$ & $63(20.1 \%)$ & $119(18.3 \%)$ & \\
\hline 3 & 43 (12.8\%) & $40(12.7 \%)$ & 83 (12.8\%) & \\
\hline Oral secretion grade & & & & 0.628 \\
\hline 1 & $217(64.6 \%)$ & 205 (65.3\%) & $422(64.9 \%)$ & \\
\hline 2 & 77 (22.9\%) & 77 (24.5\%) & $154(23.7 \%)$ & \\
\hline 3 & 42 (12.5\%) & 32 (10.2\%) & $74(11.4 \%)$ & \\
\hline Success ratio & $318: 18$ (94.6\%) & $303: 11$ (96.5\%) & $621: 29(95.5 \%)$ & 0.263 \\
\hline $\begin{array}{l}\text { Intubation time } \\
\text { (sec, in success cases only) }\end{array}$ & $\begin{array}{c}\text { Mean } 55 \pm 54 \\
\text { Median } 35.5 \\
\text { IQR }(22-61)\end{array}$ & $\begin{array}{c}\text { Mean } 54 \pm 50 \\
\text { Median } 35.0 \\
\text { IQR }(21-63)\end{array}$ & $\begin{array}{c}\text { Mean } 54 \pm 52 \\
\text { Median } 35.0 \\
\text { IQR }(21-63)\end{array}$ & 0.817 \\
\hline
\end{tabular}

Datas are expressed as number of patients $(\%)$, mean \pm standard deviation. Fisher's exact test or $\chi 2$ test was used for categorical variables and the Student's t-test or Mann-Whitney U-test was used for continuous variables.

$\mathrm{BMI}$, body mass index; ASA PS, American Society of Anesthesiologist physical status; IQR, inter quartile range.

group are compared and presented in Table 2. The patient's sex, age, height, weight, Mallampati, and laryngoscopic view grade did not affect the success rate of FNI ( $\mathrm{P}>0.05)$. BMI, the number of FNI performed by residents $(\mathrm{P}=0.03)$, secretion $(\mathrm{P}<0.001)$, and bleeding $(\mathrm{P}<0.001)$ grades influenced the success rate. The Cormack and Lehane laryngoscopic grades tended to have higher grades in the failure group, but logistic regression analysis did not show a statistically significant difference. Statistically significant differences were found in bleeding, secretion, and BMI. In particular, there was a significant difference $(\mathrm{P}<0.05)$ for secretion grade 3 and bleeding grades 2 and 3, and their odds ratios were 6.65, 5.23, and 28.4, respectively (Table 3). The AUCs or ROC curve of bleeding and secretion were 0.864 and 0.798, respectively, but the AUC of BMI, the number 
Table 2. Analysis of factors affecting success and failure of fiberoptic nasotracheal intubation

\begin{tabular}{|c|c|c|c|c|}
\hline & Success & Fail & Total & P-value \\
\hline No. of Patients & $621(95.5 \%)$ & $29(4.5 \%)$ & 650 & \\
\hline Gender & & & & 0.262 \\
\hline Male & $318(94.6 \%)$ & $18(5.4 \%)$ & $336(100 \%)$ & \\
\hline Female & $303(96.5 \%)$ & $11(3.5 \%)$ & $314(100 \%)$ & \\
\hline Age & $35.3 \pm 16.9$ & $30.2 \pm 14.4$ & $35.1 \pm 16.9$ & 0.111 \\
\hline Height & $165.5 \pm 9.2$ & $166.1 \pm 8.9$ & $165.6 \pm 9.3$ & 0.759 \\
\hline Weight & $62.6 \pm 11.2$ & $66.3 \pm 15.1$ & $62.8 \pm 12.2$ & 0.111 \\
\hline $\mathrm{BMl}$ & $22.7 \pm 3.3$ & $24.0 \pm 5.6$ & $22.8 \pm 3.5$ & 0.045 \\
\hline Order of FNIs performed by resident & $26 \pm 17$ & $20 \pm 14$ & $26 \pm 17$ & 0.031 \\
\hline ASA PS & & & & 0.481 \\
\hline 1 & $487(95.7 \%)$ & $22(4.3 \%)$ & $509(100 \%)$ & \\
\hline 2 & $124(95.4 \%)$ & $6(4.6 \%)$ & $130(100 \%)$ & \\
\hline 3 & $10(90.9 \%)$ & $1(9.1 \%)$ & 11 (100\%) & \\
\hline Tube size (mm) & & & & 0.318 \\
\hline 5.5 & $2(100 \%)$ & $0(0 \%)$ & $2(100 \%)$ & \\
\hline 6.0 & $8(100 \%)$ & $0(0 \%)$ & $8(100 \%)$ & \\
\hline 6.5 & $300(96.8 \%)$ & $10(3.2 \%)$ & $310(100 \%)$ & \\
\hline 7.0 & 311 (94.2\%) & $19(5.8 \%)$ & $330(100 \%)$ & \\
\hline Nasal bleeding grade & & & & $<0.001$ \\
\hline 1 & 445 (99.3\%) & $3(0.7 \%)$ & $448(100 \%)$ & \\
\hline 2 & 114 (95.8\%) & $5(4.2 \%)$ & $119(100 \%)$ & \\
\hline 3 & $62(74.7 \%)$ & 21 (25.3\%) & 83 (100\%) & \\
\hline Oral secretion grade & & & & $<0.001$ \\
\hline 1 & $416(98.6 \%)$ & $6(1.4 \%)$ & 422 (100\%) & \\
\hline 2 & 149 (96.8\%) & $5(3.2 \%)$ & $154(100 \%)$ & \\
\hline 3 & $56(75.7 \%)$ & $18(24.3 \%)$ & 74 (100\%) & \\
\hline Malampati grade & & & & 0.057 \\
\hline 1 & $334(97.5 \%)$ & $10(2.5 \%)$ & $315(100 \%)$ & \\
\hline 2 & 211 (94.6\%) & $12(5.4 \%)$ & $189(100 \%)$ & \\
\hline 3 & $63(92.6 \%)$ & $5(7.4 \%)$ & 57 (100\%) & \\
\hline 4 & $13(86.7 \%)$ & $2(13.3 \%)$ & $15(100 \%)$ & \\
\hline Laryngeal view grade & & & & 0.110 \\
\hline 1 & 451 (96\%) & $19(4 \%)$ & 470 (100\%) & \\
\hline 2 & 105 (95.5\%) & $5(4.5 \%)$ & $110(100 \%)$ & \\
\hline 3 & 59 (95.2\%) & $3(4.8 \%)$ & $62(100 \%)$ & \\
\hline 4 & $6(75 \%)$ & $2(25 \%)$ & $8(100 \%)$ & \\
\hline
\end{tabular}

Data are expressed as number of patients (\%), mean \pm standard deviation. Fisher's exact test or $\chi 2$ test was used for categorical variables, and the Student's t-test or Mann-Whitney U-test was used for continuous variables.

ASA PS, American Society of Anesthesiologist physical status; BMI, body mass index; FNI, fiberoptic nasotracheal intubation.

of FNI performed by residents, Mallampati, and laryngoscopic view grade were $0.527,0.616,0.614$, and 0.544 (Fig. 2).

\section{DISCUSSION}

This study analyzed data for the purpose of FNI teaching in the second year of anesthesiology resident in patients who did not have an unusual difficult airway. After FNI training using hands-on models, the residents performed FNI under the guidance of the dental anesthesiologist more than five times, and then measured the FNI time to be used in this study [5]. The overall research system followed the Smith et al. framework [6]. Unlike Smith's study, the RAE tube was inserted into the nasal cavity first, and fibroscope was inserted into the tube, which was presented by Ovassapian [10]. This 
Table 3. Logistic regression of individual factors affecting success and failure of fiberoptic nasotracheal intubation

\begin{tabular}{|c|c|c|c|c|c|}
\hline & $\mathrm{B}$ (SE) & WALD & Degree of freedom & P-value & Odd ratio $(95 \% \mathrm{Cl})$ \\
\hline Order of FNIs performed by resident & $-0.028(0.015)$ & 3.343 & 1 & 0.068 & $0.973(0.945-1.002)$ \\
\hline Nasal bleeding grade & & 23.195 & 2 & $<0.001$ & \\
\hline Grade 2 & $1.654(0.8)$ & 4.276 & 1 & 0.039 & $5.23(1.09-25.087)$ \\
\hline Grade 3 & $3.346(0.742)$ & 20.365 & 1 & $<0.001$ & $28.4(6.639-121.483)$ \\
\hline Oral secretion grade & & 12.916 & 2 & 0.002 & \\
\hline Grade 2 & $0.107(0.707)$ & 0.023 & 1 & 0.879 & $1.113(0.279-4.447)$ \\
\hline Grade 3 & $1.895(0.638)$ & 8.816 & 1 & 0.003 & $6.651(1.904-23.233)$ \\
\hline Mallampati grade & & 6.129 & 3 & 0.106 & \\
\hline Grade 2 & $1.227(0.558)$ & 4.837 & 1 & 0.028 & $3.41(1.143-10.176)$ \\
\hline Grade 3 & $0.499(0.754)$ & 0.439 & 1 & 0.508 & $1.648(0.376-7.218)$ \\
\hline Grade 4 & $2.233(1.21)$ & 3.405 & 1 & 0.065 & $9.332(0.87-100.051)$ \\
\hline Laryngeal view grade & & 1.347 & 3 & 0.718 & \\
\hline Grade 2 & $-0.377(0.645)$ & 0.342 & 1 & 0.559 & $0.686(0.194-2.429)$ \\
\hline Grade 3 & $-0.811(0.808)$ & 1.008 & 1 & 0.315 & $0.444(0.091-2.166)$ \\
\hline Grade 4 & $0.271(1.453)$ & 0.035 & 1 & 0.852 & $1.312(0.076-22.623)$ \\
\hline BMl & $0.152(0.06)$ & 6.484 & 1 & 0.011 & $1.164(1.036-1.309)$ \\
\hline (constant) & -8.795 (1.699) & 26.789 & 1 & $<0.001$ & \\
\hline
\end{tabular}

FNI, Fibroptic nasotracheal intubation; BMI, body mass index.

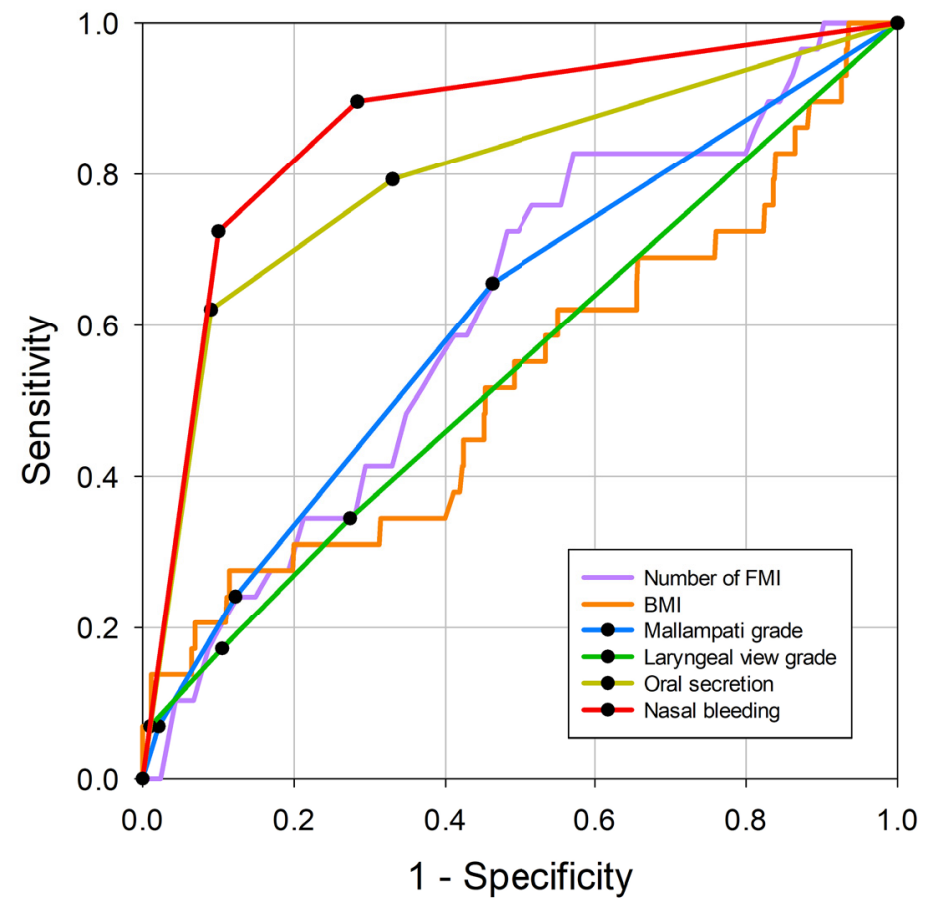

Fig. 2. Receiver operating characteristic (ROC) curve were measured. The area under the curves (AUC) of bleeding, secretion were 0.864 and 0.798 , respectively, but the AUC of body mass index (BMI), the number of fibroscopic nasotracheal intubation (FNI) performed by residents, Mallampati, and laryngoscopic view grade were $0.527,0.616,0.614$, and 0.544 , respectively.

is because if the difficult NTI is predicted in advance, awake FNI will be implemented; however, if the unexpected difficult NTI is shows up, the fibroscopic NTI should be implemented, and the endotracheal tube will already be inserted into the nasal cavity.
Before tracheal intubation, the anesthesiologist evaluates airway difficulty, such as neck mobility, mouth opening range [11], thyromental distance [12], and Mallampati grade $[13,14]$. Moreover, a method using radiographic findings as an airway evaluation has been introduced 
recently [15]. In addition, the difficulty of endotracheal intubation is evaluated through the evaluation of Cormack-Lehane laryngoscopic grade during intubation $[9,16]$. However, there are few reports that can predict the difficulty of FNI, and in general, the difficulty is measured by the duration and success of FNI $[6,17]$.

Even in the case of NTI using direct laryngoscopy, it is important to check the vocal cord before performing intubation. Therefore, the Cormack-Lehane laryngoscopic grade affects the difficulty and severity of NTI [18]. Recently, in the case of difficult NTI, video laryngoscopy has become a good alternative $[19,20]$.

However, awake FNI is essential for patients with severe maxillofacial deformities, expecting difficult mask ventilation due to facial masses or oral disturbances, and limited mouth opening range. [1]. This study presents risk factors that can affect the difficulty of FNI.

Excessive bleeding and secretions in the oral cavity are known to be the most disturbing factor that makes intubation difficult by obscuring the view of the endoscope [5]. In this study, secretion and bleeding were found to have a statistically significant effect on the success rate of FNI $(\mathrm{P}=0.002, \mathrm{P}<0.001$ in logistic regression). This is related to the characteristics of the FNI, which is strongly influenced by visibility. In particular, bleeding was found to have a significant impact, with an odds ratio of 28.4 more than secretion (6.65). It seems that bleeding has a greater role in obstructing vision than secretion. This suggests that efforts to prevent secretion and bleeding will contribute to the success rate of FNI.

There was no statistically significant relationship between Mallampati grade, Cormack and Lehane laryngoscopic grade, and FNI success rate (Tables 2 and 3). In other words, FNI can be an alternative method even if the difficult airway predicted by Cormack \& Lehane laryngoscopic grade or intubation failure by direct laryngoscope.

Most of the bleeding that occurs during nasotracheal intubation is epistaxis from abrasion between the vessel-rich nasal mucosa and tracheal tube. There are many known ways to reduce epistaxis during nasotracheal intubation. Dipping a tracheal tube into a warm saline for thermosoftening [21-23], lubricating with xylocaine jelly [24], using a vasoconstrictor [25], using a tracheal tube with a smaller internal diameter than oral intubation [1], using radiographs to select more appropriate nostril [26], and if there is no difference between both nostrils, intubation with right nostrils is a typical way to reduce bleeding [27]. Tube passing underneath the inferior turbinate has also been recently suggested as a way to reduce epistaxis [28].

To reduce oral secretion, it is helpful to use muscarinic anticholinergic agents such as glycopyrrolate, which is also helpful for preventing bradycardia and hypotension as a premedication [29,30]. Efforts to eliminate secretion through oral suction will be of great help in reducing secretion and increasing FNI success [31].

The limitations of this study are as follows: (1) If both secretion and bleeding occur in the same patient, bias may have occurred because it was not distinguished whether secretion or bleeding affected the failed FNI. (2) The difference in sample size between FNI success and failure is large. Although the study showed a statistically significant difference, the number of patients in the failure group was small, so further studies with larger sample sizes are needed.

In conclusion, this study confirms that oral secretion and bleeding are risk factors that influence the success rate of FNI. Thus, efforts to reduce oral secretion and bleeding are expected to help increase the success rate of FNI.

\section{AUTHOR ORGIDS}

Seung-Hyun Rhee: https://orcid.org/0000-0001-6210-1796

Hye Joo Yun: https://orcid.org/0000-0003-3913-6960

Jieun Kim: https://orcid.org/0000-0002-8265-1952

Myong-Hwan Karm: https://orcid.org/0000-0002-7494-4747

Seung-Hwa Ryoo: https://orcid.org/0000-0002-7442-8531

Hyun Jeong Kim: https://orcid.org/0000-0002-9265-7549

Kwang-Suk Seo: https://orcid.org/0000-0001-5906-0639 


\section{AUHOR GONHRBMIONS}

Seung-Hyun Rhee: Writing - original draft

Hye Joo Yun: Writing - original draft

Jieun Kim: Writing - review \& editing

Myong-Hwan Karm: Writing - review \& editing

Seung-Hwa Ryoo: Writing - review \& editing

Hyun Jeong Kim: Conceptualization

Kwang-Suk Seo: Conceptualization, Data curation, Formal analysis, Investigation, Methodology, Visualization, Writing - review \& editing

DECLARATION OF CONFLICTING INTERESTS: The authors declared no potential conflicts of interest with respect to the research, authorship, and/or publication of this article. FUNDING: The authors received no financial support for the research, authorship, and/or publication of this article.

\section{REFERENCES}

1. Hall CE, Shutt LE. Nasotracheal intubation for head and neck surgery. Anaesthesia 2003; 58: 249-56.

2. Rosenstock CV, Thøgersen B, Afshari A, Christensen AL, Eriksen C, Gatke MR. Awake fiberoptic or awake video laryngoscopic tracheal intubation in patients with anticipated difficult airway management a randomized clinical trial. Anesthesiology 2012; 116: 1210-6.

3. Tsukamoto M, Hitosugi T, Yokoyama T. Awake fiberoptic nasotracheal intubation for patients with difficult airway. J Dent Anesth Pain Med 2018; 18: 301-4.

4. Ovassapian A, Yelich SJ, Dykes MH, Brunner EE. Fiberoptic nasotracheal intubation--incidence and causes of failure. Anesth Analg 1983; 62: 692-5.

5. Kim H, So E, Karm MH, Kim HJ, Seo KS. Learning fiberoptic intubation for awake nasotracheal intubation. J Dent Anesth Pain Med 2017; 17: 297-305.

6. Smith JE, Jackson AP, Hurdley J, Clifton PJ. Learning curves for fibreoptic nasotracheal intubation when using the endoscopic video camera. Anaesthesia 1997; 52: 101-6.

7. Adnet F, Borron SW, Racine SX, Clemessy JL, Fournier JL, Plaisance P, et al. The intubation difficulty scale (IDS): proposal and evaluation of a new score characterizing the complexity of endotracheal intubation. Anesthesiology 1997; 87: 1290-7.

8. Lundstrøm LH, Vester-Andersen M, Møller AM, Charuluxananan S, L'hermite J, Wetterslev J, et al. Poor prognostic value of the modified mallampati score: a meta-analysis involving 177088 patients. Br J Anaesth 2011; 107: 659-67.

9. Cormack RS, Lehane J. Difficult tracheal intubation in obstetrics. Anaesthesia 1984; 39: 1105-11.

10. Ovassapian A. Fiberoptic tracheal intubation. In: Fiberoptic Airway Endoscopy in Anesthesia and Critical Care. New York: Raven Press; 1990. pp. 57-79.

11. Hagiwara Y, Watase H, Okamoto H, Goto T, Hasegawa K, Japanese Emergency Medicine Network Investigators. Prospective validation of the modified LEMON criteria to predict difficult intubation in the ED. Am J Emerg Med 2015; 33: 1492-6.

12. Benumof JL. Both a large and small thyromental distance can predict difficult intubation. Anesth Analg 2003; 97: 1543.

13. Mallampati SR, Gatt SP, Gugino LD, Desai SP, Waraksa B, Freiberger D, et al. A clinical sign to predict difficult tracheal intubation: a prospective study. Can Anaesth Soc J 1985; 32: 429-34.

14. Kandemir T, Savli S, Unver S, Kandemir E. Sensitivity of the combination of mallampati scores with anthropometric measurements and the presence of malignancy to predict difficult intubation. Turk J Anaesthesiol Reanim 2015; 43: 7-12.

15. Liu B, Song Y, Liu K, Zhou F, Ji H, Tian Y, et al. Radiological indicators to predict the application of assistant intubation techniques for patients undergoing cervical surgery. BMC Anesthesiol 2020; 20: 238.

16. Saghaei M, Safavi MR. Prediction of prolonged laryngoscopy. Anaesthesia 2001; 56: 1198-201.

17. Delaney KA, Hessler R. Emergency flexible fiberoptic nasotracheal intubation: a report of 60 cases. Ann Emerg Med 1988; 17: 919-26.

18. Shigematsu T, Miyazawa N, Kobayashi M, Yorozu T, Toyoda Y, Morisaki H. Nasal intubation with bullard laryngoscope: a useful approach for difficult airways. 
Anesth Analg 1994; 79: 132-5.

19. Mahran EA, Hassan ME. Comparative randomised study of GlideScope ${ }^{\circledR}$ video laryngoscope versus flexible fibre-optic bronchoscope for awake nasal intubation of oropharyngeal cancer patients with anticipated difficult intubation. Indian J Anaesth 2016; 60: 936-8.

20. Kido H, Komasawa N, Ishio J, Minami T. Use of a modified mcgrath mac and tracheal tube introducer for difficult nasal intubation. J Clin Anesth 2016; 34: 255-6.

21. Kim YC, Lee SH, Noh GJ, Cho SY, Yeom JH, Shin WO, et al. Thermosoftening treatment of the nasotracheal tube before intubation can reduce epistaxis and nasal damage. Anesth Analg 2000; 91: 698-701.

22. Kim EM, Chung MH, Lee MH, Choi EM, Jun IJ, Yun $\mathrm{TH}$, et al. Is tube thermosoftening helpful for videolaryngoscope-guided nasotracheal intubation?: a randomized controlled trial. Anesth Analg 2019; 129: 812-8.

23. Seo KS, Kim JH, Yang SM, Kim HJ, Bahk JH, Yum KW. A new technique to reduce epistaxis and enhance navigability during nasotracheal intubation? Anesth Analg 2007; 105: 1420-4.

24. Nakayama M, Kataoka N, Usui Y, Inase N, Takayama $\mathrm{S}$, Miura H. Techniques of nasotracheal intubation with the fiberoptic bronchoscope. J Emerg Med 1992; 10: 729-34.
25. O'Hanlon J, Harper KW. Epistaxis and nasotracheal intubation-prevention with vasoconstrictor spray. Ir J Med Sci 1994; 163: 58-60.

26. Chi SI, Park S, Joo LA, Shin TJ, Kim HJ, Seo KS. Identifying the more suitable nostril for nasotracheal intubation using radiographs. J Dent Anesth Pain Med 2016; 16: 103-9.

27. Sanuki T, Hirokane M, Kotani J. Epistaxis during nasotracheal intubation: A comparison of nostril sides. J Oral Maxillofac Surg 2010; 68: 618-21.

28. Ahmed-Nusrath A, Tong JL, Smith JE. Pathways through the nose for nasal intubation: a comparison of three endotracheal tubes. Br J Anaesth 2008; 100: 269-74.

29. Thorburn JR, James MF, Feldman C, Moyes DG, Du Toit PS. Comparison of the effects of atropine and glycopyrrolate on pulmonary mechanics in patients undergoing fiberoptic bronchoscopy. Anesth Analg 1986; 65: 1285-9.

30. Machata AM, Gonano C, Holzer A, Andel D, Spiss CK, Zimpfer M, et al. Awake nasotracheal fiberoptic intubation: patient comfort, intubating conditions, and hemodynamic stability during conscious sedation with remifentanil. Anesth Analg 2003; 97: 904-8.

31. Roberts JT. Preparing to use the flexible fiber-optic laryngoscope. J Clin Anesth 1991; 3: 64-75. 